\title{
Optimization of concrete/steel thickness ratio in composite steel plate shear walls (CSSWs)
}

\author{
F. Hatami ${ }^{1}$, A. Rahai ${ }^{2}$ \& L. Hoseinzadeh ${ }^{3}$ \\ ${ }^{I}$ Research Institute of Petroleum Industry (R.I.P.I.) \\ \& Amirkabir University of Technology, Iran \\ ${ }^{2}$ Civil Engineering Department, Amirkabir University of Technology, \\ Iran \\ ${ }^{3}$ Civil Engineer, Iran
}

\begin{abstract}
Composite shear walls made of a thin steel plate with reinforced a concrete cover, which is attached to one or both sides of the steel plate, are the third generation of lateral load resisting shear walls. In addition to increasing resistance, ductility and energy absorption, these walls are very economical and are used in constructing tall buildings, resistance of buildings and tanks. In the present research the effect of various thicknesses of steel plate on the behavior of composite shear walls in different shear connectors has been studied. For this purpose, several different models, including moment frames, steel shear walls and composite shear walls, have been analyzed through numerical and experimental models. In composite shear walls, the number of layers of reinforced concrete cover, the distance between the shear connectors and the thickness ratio of steel plate to the thickness of concrete cover are considered as variables. Increasing the thickness ratio of the steel plate to the concrete layer up to optimum leads to reduction in the out-of plane deflection rate of the steel plate and has no effect on the performance of the composite shear wall. In addition, using two layers of concrete cover on both sides of the steel plate decreases the secondary moment.
\end{abstract}

Keywords: steel shear wall, composite shear wall, post-buckling, shear connector, concrete cover, steel plate thickness. 


\section{Introduction}

Using shear walls in different forms of reinforced concrete, steel or the combination of both as a lateral loads resisting system is the common way in structures. Reinforced concrete shear walls have been used for about 30 years, but during the past three decades a comprehensive study on steel shear walls was carried out leading to the application of this innovative system in both new structures and the reinforcement of existing structures. A shear wall with central steel plate core is similar to the vertical plate girder that is used as a lateral load resisting system in medium and high-rise buildings. The system includes separated panels with every panel internally containing two boundary beams and columns. Resistance was also created by the diagonal tension field occurring at the steel plate in combination with the flexural action of the frame. The provision in the Canadian code of design for structural steel buildings confirmed this system and provided the necessary guidance for analysis and design.

Although this modern system has the same capabilities as the other lateral load resisting systems, such as moment frames, concentrically braced frames and eccentrically braced frames, it is better than other systems in the amount of steel used and it is also easier and faster to construct, as well as having a cleaner finished level. The researches shows that this system was more economical in about $50 \%$ of cases, considering the amount of used steel to the steel moment frames, this ratio is also about $15 \%$ for concentrically braced frames. Compared with reinforced shear walls, these systems have lower weight thus decreasing the earthquake force and consequently foundation dimensions.

Steel shear walls are stiffer compared to different bracing systems, such as $\mathrm{X}$-shapes, and also with respect to the possibility of making openings in each point of the wall it is much more efficient than all other bracing systems. Furthermore, the plastic behavior of this system and the amount of energy absorption is better than other bracing systems. In this system the stress distribution was smoothed out due to greater incorporation, especially in comparison with the bracing system, which causes the suitable homogeneous behavior at the plastic ambient. One of the problems related to the system is outof plane buckling steel plate, which causes diagonal lines on the steel plate. A smoother distribution of the lines increases the system shear wall capacity. It is possible to use this capability in two ways:

- Using steel grid as a stiffener which is connected to the steel plate, (SSW).

- Using pre-cast concrete or cast I place, which is connected to the steel plate by shear connectors, (CSSW).

Composite shear wall, (CSSW), consisting of a steel plate, is usually used with a concrete cover on both sides. Of course, the cover is located on one side of the steel plate and connects the concrete to the steel plate with shear connectors, such as studs and so on. Composite shear walls are also classified into two types of composite shear walls without gaps and composite shear walls with gaps. Using this system increases the strength and ductility and also decreases the building weight. It also has perfect behavior under seismic loads. In both steel and composite shear wall systems, there is different post-buckling 
phenomenon. In steel shear walls buckling is generic and applies from resistance of the limited area of the steel plate, while in composite shear walls buckling is converted from generic to the local condition so that the whole steel plate resistance is used.

\section{Previous studies}

During the past twenty years, a substantial percentage of studies in North America and Japan concentrated on the behavior of these walls under their cyclic loading and analytical models. However, there are valuable results of researches about shear walls available to access and many major constructions were built based on the information from this system about the limitations of seismic designing at current seismic code.

\subsection{Research in Canada}

Researchers at the University of Alberta (Kulak [4] and Driver et al. [1-3]) have conducted monotonic and cyclic tests of un-stiffened steel plate shear walls. The test results indicate a ductile behavior and significant over-strength. Based on their analytical research, Thorburn et al. [5] proposed an equation for the angle of inclination of the tension field. The test indicated that the proposed equation is sufficiently accurate. Driver et al. [1-3] reported the results of cyclic testing of a four-story steel shear wall specimen. The specimen was a 1/2-scale representation of a dual system with a steel plate shear wall welded to a special moment-resisting frame. The cyclical response of the first floor steel shear wall panel indicates failure mode to local buckling of the column that had occurred during cycle 20, causing large deformation amplitudes at locally buckled areas of the column flange. Researchers at the University of British Columbia have completed a series of cyclic and shaking table tests of steel plate shear walls (Lubell et al. [6], Rezai et al. [7, 8]). In these studies, cyclic shear loads were applied to two single story specimens. The boundary frames in the specimens were moment frames resulting in a "dual" structural system. The two specimens differed only in the base gusset plate details and the top beam. For the second specimen, a stronger base connection and top beam were used. The single story specimens experienced significant inelastic deformations up to ductility of about six. The over-strength was about 1.5. The researchers concluded that the two one story specimens demonstrated that the infill steel plates significantly reduced demand on the moment-resisting frame by producing redundant diagonal story braces that alleviated the rotation demand on the beam-to-column connections.

\subsection{Research in Japan}

Takanashi et al. [9] and Mimura and Akiyama [10] have conducted some of the earliest tests of steel shear walls. Takanashi et al. conducted cyclic tests of 12 one-story and two 2-story specimens. The 12 one-story specimens had $2.1 \mathrm{~m}$ width and $0.9 \mathrm{~m}$ height. They used steel plates with about $2.3 \mathrm{~mm}, 3.2 \mathrm{~mm}$ and 
$4.5 \mathrm{~mm}$ thickness. Compared to typical building dimensions, the specimens could be considered to be 1/4-scale of prototype walls. With the exception of one specimen, all specimens had vertical or vertical/horizontal stiffeners welded on one or both sides of steel plate. The boundary frames were very stiff pin-connected frames. The specimens were loaded along their diagonals to create almost pure shear in the panels. The behavior of specimens was very ductile and drift angels in some cases exceeded 0.10 radians. The shear strengths of the specimens were well predicted by von Misses yield criterion given for pure shear as $\mathrm{V}_{\mathrm{y}}=\mathrm{A}\left(\mathrm{F}_{\mathrm{y}} / \sqrt{ } 3\right)$.

\subsection{Research in the United Kingdom}

Sabouri-Ghomi and Roberts [17] and Roberts [19] have reported results of 16 tests of steel shear panels diagonally loaded. The specimens in these tests consisted of steel plates placed within a 4-hinged frame and connected to it using bolts. Some panels had perforations. The tests indicated that all panels possessed adequate ductility and sustained four large inelastic cycles. Typical hysteresis loops presented in Sabouri-Ghomi and Roberts [17] shows specimens reaching a ductility of more than seven without any decrease in strength. The researchers concluded that the strength and stiffness linearly decreases with the increase in the perforation dimensions.

\subsection{Research in the United States}

Astaneh-Asl et al. [25] also separated evaluations on the behavior of steel and composite shear walls. In these studies, cyclic loads were applied to 3 -story specimens. The specimens were $1 / 10$ scale. The goal was to determine suggestions of seismic designing in the field [24, 25].

\subsection{Research in Iran}

Alinia et al (2004-2006) numerically evaluated on behavior thin steel shear walls. The results indicated that twisting stiffness of boundary members as ambient frame has great effect on increasing buckling elastic load, but this twisting stiff on post-buckling strength of steel plate was not effective. And increasing steel plate stiffness with stiffener or increasing thickness of plate has low effect on increasing the final strength of steel [26-28].

The results of investigations carried out by Hatami and Sabouri (2005) indicates that the kind of beam to column connection has no critical effect on behavior of plates [29].

Many different experiments were carried out by Hatami and Rahai (2008) on behavior of composite shear walls made of concrete and steel or concrete and carbon polymer fibers in research Center of Structure and Earthquake of Amirkabir Industrial University that their results are about to be published [30]. 


\section{Description of different parts of the composite shear wall system for its performance}

Steel plate is a main element in composite shear wall. Preferably, this plate is selected of steel with low yield point. For example St37 steel plate is preferred for high strength steel plate. Because St37 steel plate due to its low yield point is preferred to encourage yielding of steel plate.

The reinforced concrete cover on one side or both sides of a steel plate carries some of the story shear by developing compression diagonal field and increased strength and stiffens. Of course main role of the reinforced concrete cover is to prevent out-of plan buckling of steel plate prior to reaching yielding. Shear connectors are used to concrete is to prevent buckling of steel plate. In some case shear studs not only are subjected to shear but also to a considerable tension due to local buckling of the steel plate. For cast-in-place concrete, welded shear studs are usually used, for pre-cast concrete walls bolts can be used.

\section{Models properties and investigated parameters}

In table 1 the properties of constructed models presented for thickness of concrete cover and shear connectors arrangement and thickness of steel plate.

Table 1: $\quad$ Denomination of models (rate per $\mathrm{mm}$ ).

\begin{tabular}{|l|l|l|l|l|}
\hline No & \multicolumn{1}{|c|}{ Model } & $\begin{array}{l}\text { Thickness of } \\
\text { Concrete Layer }\end{array}$ & Studs Number & $\begin{array}{l}\text { Thickness of } \\
\text { Steel Plate }\end{array}$ \\
\hline 1 & MRF & - & - & - \\
\hline 2 & SSW & - & - & 2 \\
\hline 3 & CSW-5-3*3(3) & 50 & 9 & 2 \\
\hline 4 & CSW-5-3*8(3) & 50 & 24 & 2 \\
\hline 5 & CSW $-5-3 * 3(5)$ & 50 & 9 & 5 \\
\hline 6 & CSW-5-3*8(5) & 50 & 24 & 5 \\
\hline 7 & $\mathrm{CSW}-5-3 * 3(10)$ & 50 & 9 & 10 \\
\hline 8 & $\mathrm{CSW}-5-3 * 8(10)$ & 50 & 24 & 10 \\
\hline
\end{tabular}

\section{Geometrical properties of models}

The length of frame span that is center distance to center of both sides column is $2000 \mathrm{~mm}$ and height is also frame $1000-2000 \mathrm{~mm}$ which is center distance to center of top and bottom beams. Columns and beams sections were also double IPE2000 that were reinforced with two plates $(150 * 12)$ on the flanges.

Steel plate inscribed inside the boundary beams and columns, it is $1776^{*} 776$ long and $1776^{*} 1776 \mathrm{~mm}$ wide, and the thickness of these plates are also considered 3,5 and $10 \mathrm{~mm}$. The thickness of concrete cover is 50 and $100 \mathrm{~mm}$. there is a $30 \mathrm{~mm}$ gap between the concrete cover and the boundary elements, $716^{*} 1716,1716^{*} 1716 \mathrm{~mm}$ length and width. In order to connect the concrete 
cover with $50 \mathrm{~mm}$ thickness to steel plate using $7 \mathrm{~mm}$ diameter and $100 \mathrm{~mm}$ length bolts and for connecting the concrete cover with $100 \mathrm{~mm}$ thickness using bolt with $10 \mathrm{~mm}$ diameter and $120 \mathrm{~mm}$ length. To reinforce concrete cover thickness $50 \mathrm{~mm}$ using $6.5 \mathrm{~mm}$ diameter bars with center distance to center $65 \mathrm{~mm}$ and for concrete cover $100 \mathrm{~mm}$ using $8 \mathrm{~mm}$ diameter bars with center distance to center $85 \mathrm{~mm}$.

\section{Mechanical properties of material}

Characteristics of steel that is used in all models St37 with yield point $240 \mathrm{MPa}$ and ultimate stress $370 \mathrm{MPa}$ and the behavior of steel bilinear elastoplastic curve is applied for modeling. The concrete has also compression strength of 28 day's cylindrical core sample $45 \mathrm{Mpa}$ and its tension strength is equivalent to $3 \mathrm{MPa}$.

\section{Modeling theories}

To analyze model, the following theories were considered:

- Specimens at their lower level fixed on all directions.

- The behavior of used steel such as steel plate, beams, columns and bars inside the concrete considered bilinear.

Meshing of models was also selected so that connecting the flange to web at columns and beams profile and steel plate to the boundary elements in specimens were rigid connections. Mesh dimensions was also maximum 50*50mm. Using elements on the study, includes Solid 65 for modeling reinforced concrete and considering its crack and Shell 143 for steel plate and beams and columns and Beam188 for shear connectors.

\section{Loading}

Applied load on models:

A. Static loading: 1. Static loading up to $600 \mathrm{KN} \& 2$. Static loading so that it leads to destroy the model

B. Harmonic loading-frequency $1 / 60 \mathrm{HZ}$ and amplitude value $600 \mathrm{KN}$

At harmonic loading the cyclic loading was gyred and the rate of frequency of harmonic loading is $1 / 60 \mathrm{HZ}$ and the rate of amplitude value of the force is $600 \mathrm{KN}$ that lasted for $540 \mathrm{Sec}$.

\section{Comparing the results for the numerical and experimental models}

To construct validity of analyzed model of composite shear wall specimen $(1000 * 2000 \mathrm{~mm})$ on which the thickness of steel plate and concrete cover is 3 and $50 \mathrm{~mm}$ respectively, and height overall ratio to the span is $1 / 2$. Applied under harmonic loading and its deformation-load diagram drown and compared to the analyzed results of similar numerical model (Figure 2). This experimental model is shown in Figure 1. 


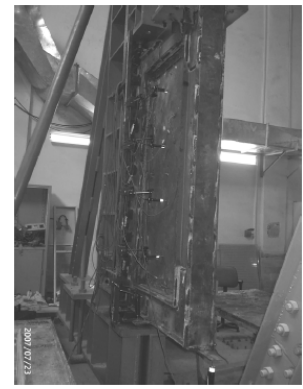

Figure 1: $\quad$ Experimental comparative model.

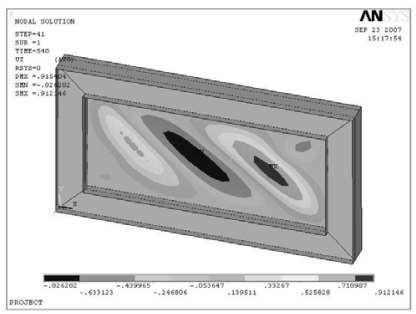

Figure 3: Out-of plane deflection of steel shear wall (SSW).

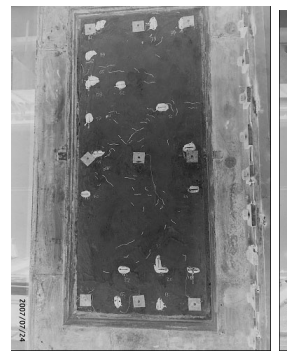

$\mathrm{CS}-5-3 * 8$

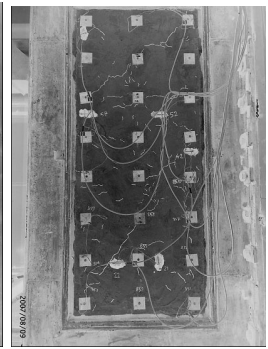

$\mathrm{CS}-5-3 * 3$

Figure 5: Comparing ultimate cracks at testing specimens.

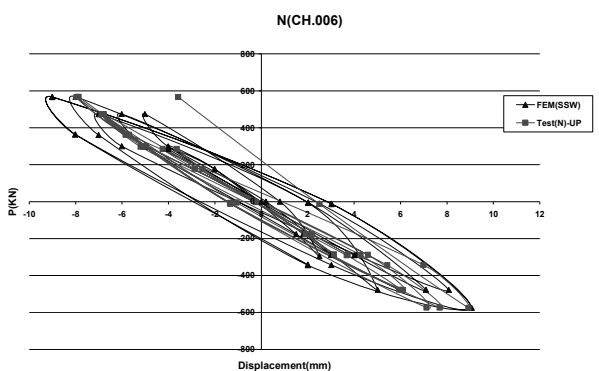

Figure 2: Comparing results of deformation-load in the numerical and experimental model for SSW.

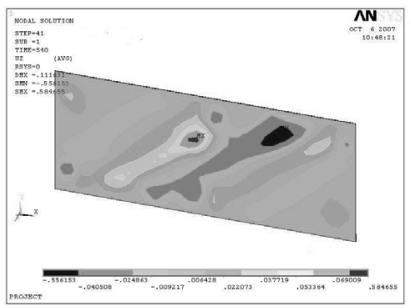

Figure 4: Out-of plane deflection of steel shear wall (CSW-5-3*3).


Figure 6: Comparing cracks of experimental with numerical models (CS-5-3*8). 
It can be observed that the discrepancy of area under hysteresis curve for numerical and experimental is less than $8 \%$.

\section{Software output results in harmonic loading}

At the last harmonic loading step, at step 41 where the time of loading is 540Sec after beginning the results of software output and experimental study graphically presented in figure 3-6 to see and compare out-of plane deflection of steel and composite shear wall and also formation of cracks in different experimental and numerical specimens.

\section{Comparing the results of numerical models analysis}

\subsection{Effect of various distances between shear connectors}

As is clear from tables 2 and 3, when the number of shear connectors increases (decreasing distance between shear connectors), the rate of lateral displacement decreased $25-30 \%$ and the rate of stiffness increased $30-35 \%$.

\subsection{Effect of various concrete cover to steel plate thickness ratios}

In figure 7 , the effect of various concrete to steel thickness ratio (invariable concrete thickness) is studied. This study includes in-plane and so, out-of plane deflection, steel stress, concrete stress and bolts stress.

As it can be observed in table 4 the increasing thickness of steel plate from $3 \mathrm{~mm}$ to $5 \mathrm{~mm}$, the rate of in-plane and out-of plane displacement decreases so that this reduction is about $35-40 \%$, but when the thickness of steel plate

Table 2: Increasing stiffness ratio and decreasing lateral displacement for models at harmonic loading.

\begin{tabular}{|l|l|l|l|l|}
\hline Model & $\begin{array}{l}\text { FRAME } \\
(\mathrm{MRF})\end{array}$ & SSW & CSW-5-3-3 & CSW-5-3-8 \\
\hline $\begin{array}{l}\text { Increasing of Stiffness } \\
\text { ratio }\end{array}$ & 1 & 2.43 & 3.03 & 3.7 \\
\hline $\begin{array}{l}\text { Decreasing of Lateral } \\
\text { Displacement ratio }\end{array}$ & 1 & 0.41 & 0.33 & 0.27 \\
\hline
\end{tabular}

Table 3: $\quad$ Various ratio out-of plane displacements for models at harmonic loading.

\begin{tabular}{|l|l|l|l|}
\hline Model & SSW & CSW-5-3-3 & CSW-5-3-8 \\
\hline $\begin{array}{l}\text { Decreasing of out of Plane } \\
\text { Displacement ratio }\end{array}$ & 1 & 0.63 & 0.37 \\
\hline
\end{tabular}




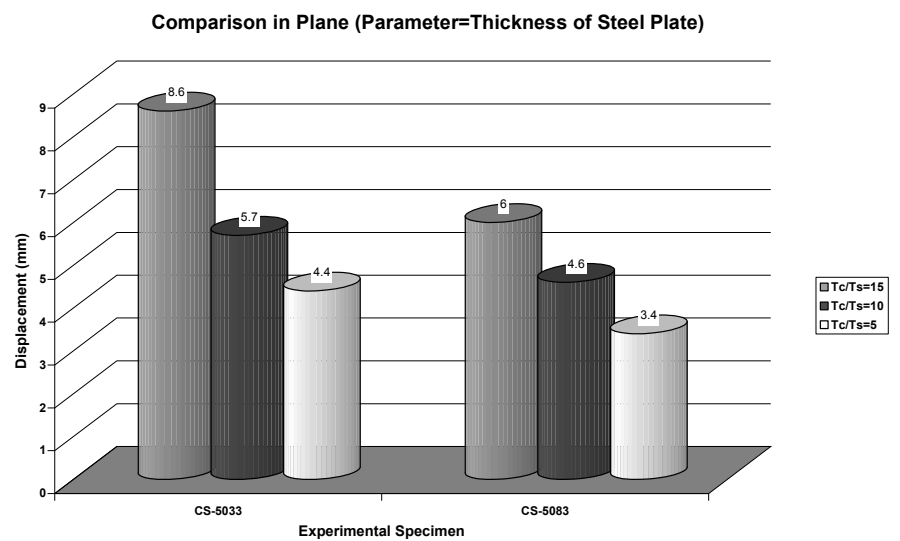

Figure 7: In-plane deflection for various thicknesses of steel plate.

Table 4: Various ratios of case study parameters and the effect of various concrete cover to steel plate thickness ratios in model 50-3-3.

\begin{tabular}{|l|l|l|l|l|}
\hline Model & $\begin{array}{l}\text { Max. Stress } \\
(\text { Steel })\end{array}$ & $\begin{array}{l}\text { Max. Stress } \\
(\text { Concrete })\end{array}$ & $\begin{array}{l}\text { Out of Plane } \\
\text { Disp. }\end{array}$ & $\begin{array}{l}\text { In Plane } \\
\text { Lateral Disp. }\end{array}$ \\
\hline $50-3 * 3(3)$ & 1 & 1 & 1 & 1 \\
\hline $50-3 * 3(5)$ & 0.59 & 0.89 & 0.6 & 0.66 \\
\hline $50-3 * 3(10)$ & 0.42 & 0.68 & 0.49 & 0.51 \\
\hline
\end{tabular}

Table 5: $\quad$ Various ratios of decrease in case study parameters for using two concrete layers on the sides.

\begin{tabular}{|c|c|c|c|c|c|}
\hline $\mathrm{Mc}$ & $\begin{array}{l}\text { In } \\
\text { Plane } \\
\text { Lateral } \\
\text { Disp. }\end{array}$ & $\begin{array}{l}\text { Out } \\
\text { of } \\
\text { Plane } \\
\text { Disp. }\end{array}$ & $\begin{array}{l}\text { Max. } \\
\text { Stress } \\
\text { (Steel } \\
\text { Plate) }\end{array}$ & $\begin{array}{l}\text { Max. } \\
\text { Stress } \\
\text { (Con. } \\
\text { Layer) }\end{array}$ & $\begin{array}{l}\text { Max. } \\
\text { Stress } \\
\text { (Shear } \\
\text { Studs) }\end{array}$ \\
\hline $50-3 * 8$ & 1 & 1 & 1 & 1 & 1 \\
\hline $2 * 50-3 * 8$ & 0.96 & 0.78 & 0.97 & 0.93 & 0.97 \\
\hline $100-3 * 8$ & 0.83 & 0.68 & 0.95 & 0.67 & 0.88 \\
\hline
\end{tabular}

increases from $5 \mathrm{~mm}$ to $10 \mathrm{~mm}$, there is no substantial in-plane decreasing and out-of plane displacement was about $10-15 \%$. Therefore it is concluded that to minimize a specific out-of plane value of thickness displacement and increment of the thickness has no effect on decreasing displacement.

As is shown in table 5 the rate of in-plane lateral displacement to the one concrete layer on one side of steel plate decreased just $4 \%$ due to use of two concrete layer on both sides. This is not substantial. So, the rate of various out-of plane displacements decreased about $22 \%$. Hence, when there is just one concrete layer on one side of steel plate, $\mathrm{P}-\Delta$ (secondary moment) considered and 
add with the rate of out-of plane displacement caused by buckling phenomenon while effect of P- $\Delta$ decreased using two concrete layer on both sides of steel plate and the rate of out-of plane displacement is due to plate buckling. Existence of a concrete layer on one side of steel plate having thickness equivalent twice thickness of every concrete on both sides decreased the rate of displacement and stresses.

\section{Summary and conclusion}

1. In case of using double concrete layers on both sides of steel plate, there are no substantial variations in the rate of in-plane lateral displacement. The composite shear wall has more capability in energy absorbing, extending the stress on more points of steel plate and ductility to the steel shear wall.

2. Increasing thickness ratio of reinforced concrete cover to the steel plate, increased stiffness and ductility of composite shear wall. Stiffness and ductility increased in field of panel size and geometry and further more it has no substantial effect.

3. Various distance between shear connectors, cause various ductility and energy absorption in composite shear wall. (for example by changing the distance of shear connectors between 440 to $195 \mathrm{~mm}$ (decrease $56 \%$ ) stress distribution between shear connectors when it is doubled the stress of steel plate will decrease about $21 \%$ and the stress of concrete plate will increase about $33 \%$. That indicate transformation a part of steel plate stress to the reinforced concrete layer increased and cause the increasing the rate of energy absorbing of composite shear wall.

4. Variations in the thickness of reinforced concrete cover to the steel plate at composite shear wall up to a specific value can increase ductility, stiffness and energy absorbing. With respect to the analysis, this ratio obtained for composite shear wall as $1: 1$ and $1: 3$ scales equivalent 7.74 and 16.4 respectively, with respect to the thickness of $7 \mathrm{~mm}$ and $3.5 \mathrm{~mm}$ of steel plate, in both cases the optimum thickness of reinforced concrete cover determined about $50 \mathrm{~mm}$ at monotonic and cyclic loading.

5. Distance between shear connectors on composite shear wall up to a specific value can improve system behavior

\section{References}

[1] Driver RG, Kulak GL, Kennedy DJL, Elwi AE. Cyclic test of four-story steel plate shear wall. J Struct Eng ASCE 1997; 124(2):112-20.

[2] Driver RG, Kulak GLDJ, Elwi AE, Kennedy L. FE and simplified models of steel plate shear wall. J Struct Eng ASCE 1997;124(2): 121-30.

[3] Driver RG, Kulak GL, Elwi AE, Kennedy DJL. FE and simplified models of steel plate shear wall. Journal of Structural Engineering ASCE 1998; 124(2):121-30. 
[4] Kulak GL. Unstiffened steel plate shear walls. In: Narayanan R, Roberts TM, editors. Structures subjected to repeated loading. New York: Elsevier; 1991. p. 237-76 [chapter 9].

[5] Thorburn L.J.; Kulak G.L.; Montgomery C.J.; "Analysis of steel plate shear walls"; Structural Engineering report No. 107; 1983; University of Alberta; Canada.

[6] Lubell AS, Prion HGL, Ventura CE, Rezai M. Unstiffened steel plate shear wall performance under cyclic loading. J Struct Eng ASCE 2000; 16(4):453-60.

[7] Rezai M.; Ventura C.E.; Prion H.G.L.; "Numerical investigation of thin unstiffened steel plate shear walls"; Proc. 12th World Conference on Earthquake Engineering; 2000.

[8] Rezai M.; Ventura C.; Prion H.; "Simplified and detailed finite element models of steel plate shear walls"; Proc. 13th world conference on earthquake engineering; Vancouver; B.C.; Canada.

[9] Takanashi Y.; Takemoto T.; Tagaki M.; "Experimental Study on Thin Steel Shear Walls and Particular Bracing under Alternative Horizontal Load"; IABSE, Lisbon, Portugal.; 1973.

[10] Mimura H.; Akiyama H.; " Load-Deflection Relationship of Earthquake Resistant Steel Shear Walls with a developed Diagonal Tension Field"; October; 1977.

[11] Sugii K.; Yamada M.; “ Steel Panel Shear Walls with and Without Concrete Covering"; 11th World Conference on Earthquake Engineering; Acapulco; Mexico; 1996.

[12] Torii S.; Teramoto T.; Kihara H.; Kitamura H.; "The Response Control Design of High-rise Building with Low Yield Steel Wall"; Proceedings on CD-Rom; 11th World Conference on Earthquake Engineering; Acapulco; Mexico; 1996.

[13] Chen SJ, Yen CZ. Application of L YP steel shear damper for seismic resistance. Struct Eng 2000; 15(1):3-21.

[14] Chen SJ, Yeh CH. Enhancement of ductility of steel beam-to-column connections for seismic resistance. Proceedings of the SSRC 1994 technical session, Structural Stability Research Council. Lehigh University, PA.

[15] Chen SJ, Yeh CH, Chu JM. Ductile steel beam-to-column connections for seismic resistance. J Struct Eng ASCE 1996; 122(11):1292-9.

[16] Chen Sheng- Jin, Jhang Chyuan. Cyclic behavior of low yield point steel shear walls. Thin-Walled Structures 44(2006) 730-738.

[17] Sabouri-Ghomi S, Roberts TM. Nonlinear dynamic analysis of steel plate shear walls including shear and bending deformations. Engineering Structures 1992;14(5):309-17.

[18] Sabouri-Ghomi S, Ventura CE, Kharrazi MHK. Shear analysis and design of ductile steel plate walls. J Struct Eng ASCE 2005; 131(6): 878-89.

[19] Roberts T.M.; "Seismic Resistance of Steel Plate Shear Walls"; Engineering Structures 17 (1995), 344-351.

[20] Caccese V, Elgaaly M, Chen R. Experimental study of thin steel-plate shear walls under cyclic load. J Struct Eng ASCE 1991; 119(2): 573-88. 
[21] Elgaaly M, Caccse V, Du C. Postbuckling behavior of steel-plate shear walls under cyclic loads. J Struct Eng ASCE 1993; 119(2): 588-605.

[22] Elgaaly M, Liu Y. Analysis of thin steel plate shear walls. Journal of Structural Engineering ASCE 1997; 123(11):1487-96.

[23] Elgaaly M. Thin steel plate shear walls behavior and analysis. Thin-Walled Structures 1998; 32:151-80.

[24] Zhao Q, Astaneh-Asl A. Cyclic behavior of traditional and innovative composite shear walls. J Struct Eng ASCE 2004.

[25] Astaneh-Asl A. Seismic behavior and design of steel shear walls. Steel TIPS report. Moraga (CA): Structural steel educational council; 2001.

[26] Alinia MM. A study into optimization of stiffeners in plates subjected to inplane shear loads. Thin-Walled Structures 2005; 43(4):845-60.

[27] Alinia MM, Dastfan M. Effect of surrounding members on shear buckling of panels. Thin-Walled Structures 2004

[28] Alinia MM, Dastfan M. Behavior of thin steel plate shear walls regarding frame members. Journal of Constructional Steel Research 62 (2006), 730738.

[29] Hatami, F. \& Sabouri, S., Behavior of Steel Plate Shear Walls in Earthquake Due to Change of Rigidity of the Internal Storey Beams. Amirkabir Journal, Vol. 15, No 60-2, Civil Engineering, Tehran, IRAN, Fall \& Winter 2004-2005.

[30] Hatami, F, Rahai, A. Performance Evaluation and Optimization of Composite Shear Wall. Ph.D. Dissertation, Amirkabir University of Technology, January 2008. 